\title{
The role of prenatal alcohol exposure in abruptio placentae
}

\author{
M M du Toit, M Smith, H J Odendaal
}

\begin{abstract}
Objective. To investigate the association between preconception and prenatal alcohol use and abruptio placentae.

Methods. A case-control study of women with the clinical diagnosis of abruptio placentae, 65 cases and 66 controls, at Tygerberg Academic Hospital, Western Cape, South Africa. Women in whom a retroplacental blood clot, covering at least $15 \%$ of the placental surface, was found at delivery at 24 weeks' gestation or later were asked to complete a timeline follow-back questionnaire to determine their alcohol intake 12 and 3 months before and during pregnancy. The same questionnaire was administered to a control group of high-risk women who had no antepartum haemorrhage.

Outcome. Women who drank alcohol 12 months before conception were more than 4 times more likely to develop abruptio placentae than the control group (odds ratio (OR) 4.49, $p=0.00009$ ).
\end{abstract}

Women who drank alcohol 3 months prior to conception were 3 times more likely to develop abruptio placentae than the control group (OR 3.06, $p=0.003$ ). Drinking alcoholic beverages during pregnancy carried a more than 3 times greater risk of developing abruptio placentae (OR 3.52, $p=0.0006$ ). In the study group, women consumed a mean of 13.6, 12.0 and 11.2 standard drinks in a typical week at 12 and 3 months before and during pregnancy, respectively. The study group demonstrated a binge-drinking pattern, with two to four sessions per month.

Conclusion. An association was found between preconception and prenatal consumption of alcohol and abruptio placentae.

S Afr Med J 2010; 100: 832-835
Abruptio placentae is the most common cause of stillbirth in South Africa. ${ }^{1}$ At Tygerberg Academic Hospital (TBH), a tertiary referral hospital in Cape Town, perinatal mortality data from July 2006 to June 2007 demonstrated that placental abruption was the direct cause of $25.5 \%$ of perinatal deaths where the birth weight was $1000 \mathrm{~g}$ or more (unpublished data, Department of Obstetrics and Gynaecology, TBH). Although abruptio placentae is associated with many risk factors, such as cigarette smoking, growth restriction, hypertension and pre-eclampsia, ${ }^{2,3}$ a local study showed that $60 \%$ of 70 multigravidas who had had intrauterine deaths due to placental abruption had unremarkable previous obstetric histories. ${ }^{4}$ A high prevalence of cigarette smoking ${ }^{5}$ and consumption of alcohol during pregnancy ${ }^{6}$ have been noted in the coloured population, in which abruptio placentae is the main cause of stillbirth.

The question therefore arises whether there is an association between excessive exposure to alcohol before conception and during pregnancy and the development of placental abruption. Although epidemiological studies have reported increased rates of abruptio placentae in heavy drinkers during pregnancy, ${ }^{7-10}$ this association has not been investigated prospectively.

\section{Material and methods}

After approval by the Committee for Human Research of Stellenbosch University, this case-control study was performed between April 2006 and January 2008 to investigate the association between alcohol use during pregnancy and abruptio placentae. All possible cases of placental abruption were identified by the registrars on call in the labour ward by listing the women's names in the registrar's meeting room. Care was taken to include all cases of abruption, and not

Department of Obstetrics and Gynaecology, Tygerberg Academic Hospital, Tygerberg, W Cape

M M du Toit, MB ChB, MMed, FCOG (SA)

M Smith, MB ChB, MMed, FCOG (SA)

H J Odendaal, MB ChB, FCOG (SA), FRCOG, MD only the severe ones. One of the first two authors then verified the information on the woman's hospital chart to ensure that the inclusion criteria (a retroplacental blood clot covering $\geq 15 \%$ of the placental surface, gestational age $\geq 24$ weeks, coloured population and singleton pregnancy) and exclusion criteria (multiple pregnancy, other causes of antepartum haemorrhage and poor knowledge of Afrikaans or English, the languages in which the interviews were conducted) were applied.

Once the woman was stable in the postnatal ward, one of the first two authors explained the study to her and obtained written informed consent for participation. Care was taken to explain that the study questionnaire did not imply that lifestyle factors were possibly responsible for the placental abruption. The timeline followback approach ${ }^{11}$ was used to obtain detailed information about daily alcohol use during a typical week a year before pregnancy, 3 months before pregnancy and during pregnancy. The amount of alcohol consumed was accurately quantified by establishing the volume and type of drink, and among how many people these drinks were shared. Illustrations of containers, bottles and glasses were used to help women to identify the specific drink and the volume consumed. For example, if a participant shared $750 \mathrm{ml}$ Amarula liqueur with two drinking partners ( $250 \mathrm{ml}$ per person, alcohol content $17 \%$ ), the alcohol used per person was $34 \mathrm{~g}(250 \times 17 / 100 \times 0.8$, the specific gravity (SG) of alcohol) as well as $2000 \mathrm{ml}$ wine between the three of them ( $666.6 \mathrm{ml}$ per person, alcohol concentration $10 \%)$, the alcohol used per person was $53.3 \mathrm{~g}(666.6 \times 10 / 100 \times 0.8)$, giving a total of $87.3 \mathrm{~g}$ of absolute alcohol. For quantification of alcohol intake, a standard drink was defined as $10 \mathrm{~g}$ of absolute alcohol. ${ }^{12}$ Sections of the alcohol use disorder identification test (AUDIT) were used to assess the complications of heavy drinking. ${ }^{13}$

Additional information included marital status, level of formal education, preferred language, age at which first exposed to alcohol, presenting complaints, and details of previous deliveries (gestational ages, methods of delivery, birth weights and Apgar scores). For each study group case, a control case was selected at random from the postnatal wards in which the study patients were lying, applying the same inclusion and exclusion criteria. Control cases with placental abruption were not accepted, but other cases were selected from the same ward. 
TBH is a tertiary referral hospital and therefore receives complicated cases only, as minor problems are managed by surrounding district hospitals. Both the study and the control groups were therefore selected from complicated obstetric referrals.

For statistical analysis STATA Statistics and Data Analysis Version 10.0, Special Edition, was used. The number and percentage of qualitative variables and the mean and standard deviation (SD) of quantitative data were calculated. Comparisons between the mean values of quantitative variables were calculated using Student's $t$-test, while the chi-square test was used for qualitative data. A $95 \%$ confidence interval (CI) was calculated where applicable. All tests of significance used were at the $5 \%$ level of significance.

\section{Results}

Initially there were 66 women in both the study and the control groups, but a case was excluded from the study group because the gestational age was just below 24 weeks. Five women in the study group had a history of an abruption in a previous pregnancy, in contrast to one in the control group. Mean parity and gravidity did not differ significantly. Study cases delivered significantly earlier than

Table I. Patient characteristics

\begin{tabular}{|c|c|c|c|}
\hline & $\begin{array}{l}\text { Cases } \\
(N=65)\end{array}$ & $\begin{array}{l}\text { Controls } \\
(N=66)\end{array}$ & $p$-value \\
\hline Gravidity ( $N$ (mean)) & $65(2)$ & $66(2)$ & 0.8656 \\
\hline Parity $(N$ (mean)) & $65(2)$ & $66(2)$ & 0.9899 \\
\hline Age (yrs) (N (mean)) & $65(26.3)$ & $66(27.6)$ & 0.2863 \\
\hline $\begin{array}{l}\text { Gestational age (wks) } \\
(N \text { (mean)) }\end{array}$ & $65(32.9)$ & $66(36.8)$ & $<0.00001$ \\
\hline \multicolumn{4}{|l|}{ GA determined by $(N(\%))$} \\
\hline Symphysis-fundal height & $20(30.8)$ & $15(23.1)$ & \\
\hline Early ultrasound (EUS) & $27(41.5)$ & $31(47.7)$ & \\
\hline $\begin{array}{l}\text { Dates (last menstrual } \\
\text { period) }\end{array}$ & $9(13.8)$ & $13(20)$ & \\
\hline Dates + EUS & $9(13.8)$ & $7(9.2)$ & \\
\hline \multicolumn{4}{|l|}{ Marital status (N (\%)) } \\
\hline Married & $15(23.1)$ & $30(45.5)$ & 0.0070 \\
\hline Not married & $50(76.9)$ & $36(54.5)$ & \\
\hline $\begin{array}{l}\text { Mean level of highest } \\
\text { education (grade) } \\
(N \text { (mean) })\end{array}$ & $65(10)$ & $66(10)$ & - \\
\hline \multicolumn{4}{|l|}{ Language (N (\%)) } \\
\hline Afrikaans & $49(75.4)$ & $52(78.8)$ & - \\
\hline English & $6(9.2)$ & $3(4.5)$ & - \\
\hline Both & $10(15.4)$ & $11(16.7)$ & - \\
\hline Non-smokers $(N(\%))$ & $18(27.7)$ & $28(42.4)$ & \\
\hline Smokers $(N(\%))$ & $47(72.3)$ & $38(57.6)$ & 0.0785 \\
\hline $\begin{array}{l}\text { Mean number of } \\
\text { cigarettes/day smoked } \\
\text { before pregnancy }\end{array}$ & 7.7 & 8.5 & \\
\hline $\begin{array}{l}\text { Mean number of } \\
\text { cigarettes/day smoked } \\
\text { during pregnancy }\end{array}$ & 4.6 & 5.2 & \\
\hline
\end{tabular}

control cases. Ultrasound was most commonly used to determine the gestational age (Table I). Significantly more participants (76.9\%) in the study group were not married compared with the control group (54.5\%). Cigarette smoking during pregnancy was reported in $72.3 \%$ of the study group and $57.6 \%$ of the control group $(p=0.0785)$ (Table I).

In the study group, the most common presenting symptoms were antepartum haemorrhage/abdominal tenderness. In the control group, preterm labour was the most common indication for admission. The frequency of operative deliveries did not differ between the two groups, but birth weights and 5-minute Apgar scores were significantly lower in the study group (Table II). Forty per cent of the study group (26 women) reported alcohol-related problems compared with $5 \%(2)$ in the control group $(p<0.0001)$.

Fifty-two women $(80 \%)$ in the study group reported alcohol use 12 months before pregnancy. In the control group, 31 women (47\%) reported the same use (OR 4.49; 95\% CI 1.95 - 10-62; $p=0.00009$ ). Alcohol use 3 months before pregnancy was reported by 49 women (75\%) in the study group, but by 33 women (50\%) in the control group (OR 3.06; 95\% CI 1.458 - 6.435; $p=0.003$ ). Alcohol use during pregnancy was reported by 37 women $(57 \%)$ in the study group and 18 (27\%) in the control group (OR 3.52; 95\% CI 1.16 - 7.85; $p=0.0006)$. Twelve (18\%) women in the study group never consumed alcohol, in comparison with 28 (42\%) in the control group (OR 3.25; $95 \%$ CI $1.39-7.8 ; p=0.003$ ). Table III lists the amount and frequency of drinking in the study and control groups before and during pregnancy. The number of standard drinks taken during a typical week by women in the study group was almost double that of the control group.

Twenty-two women (34\%) in the study group had pre-eclampsia, in contrast to $11(17 \%)$ in the control group (OR 2.56; 95\% CI 1.04 6.36; $p=0.02)$. In the study group, $47(72 \%)$ smoked cigarettes in contrast to $38(58 \%)$ in the control group (OR 1.92; 95\% CI 0.87 $4.82 ; p=0.08)$.

\section{Discussion}

Women who had drunk more alcohol 12 months before, 3 months before and during pregnancy had a higher risk of developing abruptio placentae than women who did not use alcohol. Alcohol consumption

Table II. Indication for admission to labour ward and labour-related outcome

\begin{tabular}{llll}
\hline & $\begin{array}{l}\text { Cases } \\
(N=65)\end{array}$ & $\begin{array}{l}\text { Controls } \\
(N=66)\end{array}$ & $p$-value \\
\hline APH/tenderness $(N(\%))$ & $27(41.6)$ & $0(0)$ & - \\
APH $(N(\%))$ & $21(32.3)$ & $3(4.5)$ & $<0.0001$ \\
Pre-eclampsia $(N(\%))$ & $5(7.7)$ & $14(21.1)$ & 0.0280 \\
Fetal distress $(N(\%))$ & $10(15.4)$ & $6(9.1)$ & 0.2714 \\
In labour $(N(\%))$ & $2(3.0)$ & $43(65.2)$ & $<0.0001$ \\
Caesarean section $(N(\%))$ & $33(50.8)$ & $32(48.5)$ & - \\
Vaginal delivery $(N(\%))$ & $32(49.2)$ & $34(51.5)$ & - \\
Birth weight $(\mathrm{g})(N($ mean $))$ & $65(1932)$ & $66(2831)$ & $<0.0001$ \\
Apgar score -5 min & $65(4.1)$ & $66(9.2)$ & $<0.0001$ \\
$(N($ mean $))$ & & & - \\
Stillbirths $(N(\%))$ & $17(26.1)$ & $0(0)$ & - \\
APH = antepartum haemorrhage. & & & \\
\hline
\end{tabular}


Table III. Number of standard drinks taken during a typical week and frequency of drinking before and during pregnancy

\begin{tabular}{|c|c|c|c|c|c|c|c|c|c|c|c|c|c|c|}
\hline & \multicolumn{6}{|c|}{ No. of drinks* } & \multicolumn{8}{|c|}{ Frequency of drinking } \\
\hline & \multicolumn{2}{|c|}{ Mean } & \multicolumn{2}{|c|}{ Min } & \multicolumn{2}{|c|}{$\operatorname{Max}$} & \multicolumn{2}{|c|}{ Monthly/less } & \multicolumn{2}{|c|}{$\begin{array}{c}2 \text { - } 4 \text { times/ } \\
\text { month }\end{array}$} & \multicolumn{2}{|c|}{$\begin{array}{c}2-3 \text { times/ } \\
\text { week }\end{array}$} & \multicolumn{2}{|c|}{$\begin{array}{c}\geq 4 \text { times/ } \\
\text { week }\end{array}$} \\
\hline & S & $\mathrm{C}$ & S & $\mathrm{C}$ & S & $\mathrm{C}$ & S & $\mathrm{C}$ & S & $\mathrm{C}$ & $\mathrm{S}$ & $\mathrm{C}$ & S & $\mathrm{C}$ \\
\hline 12 months before & 13.6 & 6.6 & 1.9 & 0.9 & 53.1 & 19.8 & 14 & 16 & 36 & 14 & 1 & 1 & 1 & 0 \\
\hline 3 months before & 12.0 & 6.4 & 3.2 & 0.5 & 22.2 & 15.2 & 13 & 15 & 35 & 17 & 0 & 1 & 1 & 0 \\
\hline $\begin{array}{l}\text { During } \\
\text { pregnancy }\end{array}$ & 11.2 & 7.6 & 3.3 & 1.1 & 62.4 & 26.4 & 11 & 8 & 25 & 10 & 0 & 0 & 1 & 0 \\
\hline $\begin{array}{l}\text { *No. of standard drinks } \mathrm{C} \\
\mathrm{S}=\text { study group; } \mathrm{C}=\mathrm{cont}\end{array}$ & $\begin{array}{l}\text { nsumed } \\
\text { ol group. }\end{array}$ & a ts & & & & & & & & & & & & \\
\hline
\end{tabular}

was also significantly higher in the abruption group than in the control group, ranging from 112 to $136 \mathrm{~g}$ per week. Although this could be regarded as moderate drinking, defined as $70-140 \mathrm{~g}$ of alcohol per week, ${ }^{14}$ most women had a pattern of binge drinking.

It is not clear by what mechanism exposure to heavy alcohol consumption could cause abruptio placentae. However, it is likely that placentation in early pregnancy is affected..$^{15}$ In addition, poor placental function, reflected by low levels of pregnancy-associated plasma protein $\mathrm{A}$ in the first trimester, was associated with more stillbirths, some of which were unexplained and others caused by placental abruption. ${ }^{16}$ Furthermore, many stillbirths, including unexplained ones, are related to poor placental function. ${ }^{17}$ It is likely that folate deficiency also plays a role, as heavy drinking has an adverse effect on folate mechanism. ${ }^{18,19}$ It is therefore possible that certain cases of placental abruption are associated with folate deficiency. It is interesting to note that infants with fetal alcohol spectrum disorders have more atrial and ventricular septal defects than normal controls..$^{20}$ In addition, the prevalence of these cardiac defects is higher in infants where the pregnancy was complicated by placental abruption. ${ }^{21}$ It is therefore possible that the development of both the heart and the placenta may be affected by alcohol exposure in early pregnancy. A meta-analysis has shown that the preconception administration of folic acid-containing multivitamins reduced the frequency of many congenital abnormalities, including cardiovascular defects. ${ }^{22}$ It is possible that some of these prevented defects could have been alcohol-related. Another possible mechanism is oxidative stress caused by exposure to alcohol. ${ }^{23,24}$

The higher frequency of pre-eclampsia in the control group is surprising, but it may due to selection of preterm labour for the control group. Preterm delivery is common in pre-eclampsia. ${ }^{25}$ No reports could be found on whether an association exists between heavy drinking in early pregnancy and the later development of pre-eclampsia. Our finding that cigarette smoking did not differ between the two groups was surprising, as smoking is a known risk factor for placental abruption. ${ }^{2,26}$ However, this was a small series and both groups had a high prevalence of cigarette smoking, with a trend towards more smoking in the abruption group. It is also possible that some of the known adverse effects of cigarette smoking may indeed be due to drinking, as most heavy drinkers also smoke cigarettes (Tygerberg Hospital, unpublished data), and many studies on cigarette smoking did not include drinking as a variable.

The fact that there were 32 intra-uterine deaths in the study group but no deaths in the control group demonstrates the high fetal mortality associated with placental abruption. Unfortunately no autopsies were done and no placentas sent for histological examination, as little is known about the effects of heavy drinking on the human placenta. ${ }^{15}$ Financial constraints at hospitals in developing countries limit the use of non-essential special investigations.

Limitations of this study include the introduction of selection bias, since the control group was also selected from women referred to a tertiary hospital, as reflected by their high frequency of preterm labour and caesarean section. As exposure to alcohol during pregnancy is also a risk factor for preterm labour, ${ }^{27}$ selection of the control group from a low-risk population could have resulted in a greater difference in alcohol consumption between the study and control groups. A further study defect is that no information was obtained on maternal nutrition, as this could have played a role in the poor development of placenta or abruption in some cases. Further studies are needed to confirm the association between drinking alcohol during pregnancy and abruption, in order to determine what the mechanism is and whether the prevalence of abruption could be reduced by drinking cessation programmes.

We wish to thank Dr G A Petro for his help with the statistical analyses.

Disclosure of interests. The authors are not aware of any interests to be disclosed.

Contribution to authorship. The first two authors conducted all the research relating to the questionnaires, entered the data and prepared the manuscript. The last author helped with the planning of the study, analyses and finalising the manuscript.

Details of ethics approval. The study was approved by the Committee for Human Research of Stellenbosch University. Written informed consent for the study was obtained and strict confidentiality was maintained.

Funding. No funding was needed, as the study formed part of two master's degree dissertations.

\section{References}

1. Perinatal Problem Identification Programme. www.ppip.co.za (accessed 31 January 2008).

2. Castles A, Adams EK, Melvin CL, Kelsch C, Boulton ML. Effects of smoking during pregnancy. Five meta-analyses. Am J Prev Med 1999;16:208-215.

3. Hall DR, Odendaal HJ, Steyn DW, Grové D. Expectant management of early onset, severe pre-eclampsia: Hall DR, Odendaal HJ, Steyn DW, Grove D. Expectant managem
maternal outcome. Br J Obstet Gynaecol 2000;107: 1252-1257.

maternal outcome. Br J Obstet Gynaecol 2000;107: 1252-1257.
Leunen K, Hall DR, Odendaal HJ, Grové D. The profile and complications of women with placental Leunen K, Hall DR, Odendaal HJ, Grove D. The profile and comp
abruption and intrauterine death. J Trop Pediatr 2003; 49:231-234.

5. Steyn K, Yach D, Stander I, Fourie J. Smoking in urban pregnant women in South Africa. S Afr Med J 1997;87:460-463.

May PA, Gossage JP, Brooke LE, et al. Maternal risk factors for fetal alcohol syndrome in the Western Cape Provinces of South Africa: a population-based study. Am J Public Health 2005; 95:1190-1199. 7. Kaminski M, Rumeau C, Schwartz D. Alcohol consumption in pregnant women and the outcome of pregnancy. Alcohol Clin Exp Res 1978;2:155-163.

. Sokol RJ, Miller SI, Reed G. Alcohol abuse during pregnancy: an epidemiologic study. Alcohol Clin Exp Res 1980;4:135-145.

9. Marbury MC, Linn S, Monson R, Schoenbaum S, Stubblefield PG, Ryan KJ. The association of alcohol consumption with outcome of pregnancy. Am J Public Health 1983;73:1165-1168.

0. Tikkanen M, Nuutila M, Hilesmaa V. Clinical presentation and risk factors of placental abruption. Acta Obstet Gynecol Scand 2006;85:700-705.

11. Jacobson S, Chiodo LM, Sokol RJ, Jacobson JL. Validity of maternal report of prenatal alcohol, cocaine, and smoking in relation to neurobehavioral outcome. Pediatrics 2002;109:815-825. 
12. http://www.alcohol.gov.au/internet/alcohol/publishing.nsf/Content/standard (accessed 2 February 2008).

13. Göransson M, Magnusson A, Heilig M. Identifying hazardous alcohol consumption during pregnancy: implementing a research-based model in real life. Acta Obstet Gynecol Scand 2006;85:657-562.

14. United States Department of Agriculture and United States Department of Health and Human Services. Alcoholic beverages. In: Dietary Guidelines for Americans. Washington, DC: US Government Printing Office, 2005:43-46 (Chapter 9).

15. Burd L, Roberts D, Olson M, Odendaal H. Ethanol and the placenta: A review. J Matern Fetal Neonatal Med 2007;20:361-375.

6. Smith GC, Crossley JA, Aitken DA, et al. First-trimester placentation and the risk of antepartum stillbirth. JAMA 2004;292:2249-2254.

7. Smith GC, Fretts RC. Stillbirth. Lancet 2007;370:1715-1725

18. Stark KD, Pawlosky RJ, Beblo S, et al. Status of plasma folate after folic acid fortification of the food supply in pregnant African American women and the influences of diet, smoking, and alcohol consumption. Am J Clin Nutr 2005:81:669-677.

19. Chiuve SE, Giovannucci EL, Hankinson SE, et al. Alcohol intake and methylenetetrahydrofolate reductase polymorphism modify the relation of folate intake to plasma homocysteine. Am J Clin Nutr 2005;82:155-162
20. Burd L, Deal E, Rios R, Adickes E, Wynne J, Klug MG. Congenital heart defects and fetal alcohol spectrum disorders. Congenit Heart Dis 2007;2:250-255.

1. Raymond EG, Mills JL. Placental abruption. Maternal risk factors and associated fetal conditions. Act Obstet Gynecol Scand 1993;72:633-639.

22. Goh YI, Bollano E, Einarson TR, Koren G. Prenatal multivitamin supplementation and rates of congenital anomalies: a meta-analysis. J Obstet Gynaecol Can 2006;28:680-689.

3. McDonough KH. Antioxidant nutrients and alcohol. Toxicology 2003;189:89-97.

24. Chaudhuri JD. Alcohol and the developing fetus - a review. Med Sci Monit 2000;6:1031-1041

25. Odendaal HJ, Steyn DW, Norman K, Kirsten GF, Smith J, Theron GB. Improved perinatal mortality rates in 1001 patients with severe pre-eclampsia. S Afr Med J 1995;85:1071-1076.

26. Hogberg V, Rasmussen S, Irgens LM. The effect of smoking and hypertensive disorders on abruptio placentae in Norway 1999-2002. Acta Obstet Gynecol Scand 2007;86:304-309.

27. Dew PC, Guillory VI, Okah FA, Cai J, Hoff GL. The effect of health compromising behaviors on preterm births. Matern Child Health J 2007:11:227-233.

\title{
Bacteria isolated from bloodstream infections at a tertiary hospital in Dar es Salaam, Tanzania - antimicrobial resistance of isolates
}

\author{
S Moyo, S Aboud, M Kasubi, S Y Maselle
}

Objective. A bloodstream infection (BSI) is a life-threatening condition. We studied the causative agents of BSIs and antimicrobial susceptibility patterns of bacterial isolates at Muhimbili National Hospital (MNH) in Dar es Salaam, Tanzania.

Methods. A retrospective analysis of blood culture results obtained at MNH from January 2005 to December 2009 was done. Blood culture isolates judged to be clinically significant and antimicrobial susceptibility results of the bacteria were included. The frequencies and proportions of bacteria isolated and antimicrobial susceptibility results were analysed and compared using Pearson's chi-square test and Fisher's exact test where applicable, or the Mann-Whitney U-test.

Results. A total of 13833 blood cultures were performed. Bacterial pathogens were detected in 1855 (13.4\%), Gram-positive bacteria (1 523; 82.1\%) being significantly more prevalent than Gramnegative bacteria $(332 ; 17.9 \%)(p=0.008)$. The most common bacterial pathogens isolated were coagulase-negative staphylococci
(CoNS) (1 250; 67.4\%), S. aureus (245; 13.2\%), Escherichia coli (131; $7 \%)$ and Klebsiella spp. (130; 7.0\%). All bacteria isolated showed high resistance to penicillin $\mathrm{G}(70.6 \%)$, tetracycline $(63.8 \%)$, cefotaxime $(62.5 \%)$ and ampicillin (62.3\%). Moderate to high resistance was seen against chloramphenicol (45.2\%), erythromycin (35.0\%), ciprofloxacin $(29.3 \%)$, co-trimoxazole $(25.0 \%)$ and gentamicin (23.5\%). Of S. aureus isolates, $23.3 \%$ were resistant to methicillin.

Conclusions. CoNS accounted for two-thirds of the bacterial pathogens isolated. High-level resistance was seen to first-line and inexpensive antimicrobial agents. Routine screening for extendedspectrum beta-lactamase production and methicillin resistance among Gram-negative rods and $S$. aureus from blood cultures should be instituted to monitor spread of multidrug-resistant isolates.

S Afr Med J 2010; 100: 835-838.
A bloodstream infection (BSI) is a life-threatening condition that may be complicated by septic shock and death. BSI due to bacteria is an important cause of morbidity and mortality. ${ }^{1}$ Gram-negative bacteria

Department of Microbiology and Immunology, Muhimbili University of Health and Allied Sciences, Dar es Salaam, Tanzania

S Moyo, MD, MMed (Microbiology and Immunology)

S Aboud, MD, MMed (Microbiology and Immunology)

S Y Maselle, MD, PhD

Department of Laboratory Services, Microbiology Section, Central Pathology Laboratory Muhimbili National Hospital, Dar es Salaam

M Kasubi, MD, MMed (Microbiology and Immunology), PhD have been associated with more deaths than Gram-positive bacteria. Mortality due to septic shock can be as high as $60 \%$ despite treatment. A better understanding of the spectrum of pathogens causing BSI is crucial for prompt management of patients, as antimicrobial therapy greatly influences the outcome of patients with BSI. ${ }^{1}$

Over the past 20 - 30 years there have been significant changes in the causation and epidemiology of BSI. While Staphylococcus aureus and Escherichia coli continue to be the most common causative agents, there has been a substantial increase in BSI due to coagulasenegative staphylococci (CoNS).

Recent studies have reported an increasing frequency of antimicrobial resistance among microbial pathogens causing BSI in Tanzania and elsewhere, ${ }^{2,3}$ and several classes of antimicrobial agents have become less effective as a result of the emergence of antimicrobial resistance, often caused by the selective pressure of antimicrobial usage. The important emerging problems are resistance to extended-spectrum cephalosporins and fluoroquinolones in the 